\title{
Evaluation of over-etching technique in the endodontically treated tooth restoration
}

\author{
Guido Migliau, MD, DDS, PhD \\ Luca Piccoli, DDS, PhD \\ Laith Konstantinos Besharat, DDS, MSc, PhD \\ Stefano Di Carlo, MD, DDS \\ Giorgio Pompa, MD, DDS
}

Department of Oral and Maxillo Facial Sciences, School of Dentistry, "Sapienza" University of Rome, Italy

Corresponding author:

Laith Konstantinos Besharat

Department of Oral and Maxillo Facial Sciences, School of Dentistry, "Sapienza" University of Rome Viale Regina Elena, 287/A

Via Caserta, 6

00161 Rome, Italy

E-mail: besharatlk84@yahoo.it

\section{Summary}

The main purpose of a post-endodontic restoration with posts is to guarantee the retention of the restorative material. The aim of the study was to examine, through the push-out test, how bond strength between the post and the dentin varied with etching time with $37 \%$ orthophosphoric acid, before cementation of a glass fiber post. Moreover, it has been examined if over-etching (application time of the acid: 2 minutes) was an effective technique to improve the adhesion to the endodontic substrate, after highlighting the problems of adhesion concerning its anatomical characteristics and the changes after the endodontic treatment. Highest bond strength values were found by etching the substrate for $30 \mathrm{sec}$., while over-etching didn't improve bond strength to the endodontic substrate.

Key words: endodontic substrate, etching time, dental bonding, glass fiber posts.

\section{Introduction}

The development of the materials and techniques in dentistry has recently took steps forward and succeed in preserving teeth instead of extracting them. Most of these improvements were evident in conservative dentistry and in particular, adhesive dentistry.
Enamel, dentin and cementum represent different adhesive surfaces due to the composition, morphology and biomechanical characteristics $(1,2)$. Adhesion obtained through adhesive systems is both chemical and micro-mechanical, with the formation of the hybrid layer (3) and resin tags achieved through etching which increases the available surface contact with the resin (4). In endodontically treated teeth, the substrate with which adhesion is obtained is the dentin, pulp chamber and root canal $(5,6)$.

The presence of contaminants (intermediate medications, cements, gutta-percha) (7-9) the passage of irrigating solutions which destroy collagen fibers (10-12), the loss of the intrinsic humidity (13), the presence of a smear layer produced by the endodontic instruments (14) and other factors related to the endodontic treatment are an obstacle to adhesion of the post. An endodontically treated tooth is far weaker than a vital tooth, because of the loss of the dental substance (15) so the post is a key element in the post-endodontic restoration (16-18).

Adhesion problems are accentuated by the "C factor", which is very high in the post-space, like a first-class conservative cavity. The cavity shape is deeper than broader, with a consequent polymerization shrinkage stress of composite cements $(19,20)$, and is characterized by a lower accessibility and visibility of the area, which makes it difficult for correct execution of the adhesive protocols.

The principal aim of the study was to evaluate and compare the bond strength values obtained during the cementation of the glass fiber posts with etching-time.

\section{Materials and methods}

Forty dental monoradicular elements, with no decay and extracted for periodontal reasons, kept in balanced salt solution. Crown of all teeth was removed using a diamond cylindrical bur under water cooling at cemento-enamel junction, plumb to the tooth axis. Roots were treated endodontically with simultaneous technique using nickel-titanium (NiTi) instruments "Mtwo" (Sweden \& Martina), following the manufactures instructions, namely 10/.04 taper - 15/.05 taper - 20/.06 taper- 25/.06 taper. The irrigation protocol used $5 \%$ sodium hypochlorite (Niclor 5, Ogna), during the preparation, with a final irrigation for 2 minutes with $5 \%$ sodium hypochlorite warmed to $37^{\circ} \mathrm{C}$. EDTA was used at the end of preparation in order to remove smear layer. Root canal filling was carried out with the lateral condensation technique with ISO standardized gutta-percha points and cement containing epoxy resin Top Seal (Dentsply, Maillefer). Then the experimental protocol established 
the preparation of the post space, realized with Largo 1 and 2 burs at a length of $10 \mathrm{~mm}$ for each sample.

The samples were divided into four groups and restored, as following:

- Group A (10 samples): etching for 15 seconds using $37 \%$ orthophosphoric acid (Superlux Thixo etch - DMG), using a 3 steps dual-curing adhesive system (Luxabond - Total etch - DMG), dual-cured resin-composite cement (LuxaCore $D M G$ ) and glass fiber posts (LuxaPost - DMG).

- Group B (10 samples): etching for 30 seconds using $37 \%$ orthophosphoric acid (Superlux Thixo etch - DMG), using a 3 steps dual-curing adhesive system (Luxabond - Total etch - DMG), dual-cured resin-composite cement (LuxaCore $D M G$ ) and glass fiber posts (LuxaPost - DMG).

- Group C (10 samples): etching for 2 minutes using 37\% orthophosphoric acid (Superlux - Thixo etch - DMG), using a 3 steps dual-curing adhesive system (Luxabond - Total etch - DMG), dual-cured resin-composite cement (LuxaCore $D M G$ ) and glass fiber posts (LuxaPost - DMG).

- Group D or control group (10 samples): without the etching time step, using a 3 steps dual-curing adhesive system (Luxabond - Total etch - DMG), dual-cured resin-composite cement (LuxaCore $D M G)$ and glass fiber posts (LuxaPost - DMG).

\section{Preparation of the samples for the mechanical tests}

The portion of each roots corresponding to the bonded fiber post was transversally sectioned into $1 \mathrm{~mm}$ thick serial slices, using a microtome, the Micromet (Remet) posting a low-speed saw (Norton - Dia Whee/), $0.2 \mathrm{~mm}$ thick, under water-cooling operating at 2.240 spins per minute.

The sections, were realized in apical-coronal direction and each section was marked on the apical surface to put it exactly under the punch of the machine for the push-out test. A number was assigned to each root and a progressive alphabetical letter to each slice from the apical surface to the coronal one.

\section{The push-out test}

Push-out load was applied using a universal testing machine Galdabini- Sun 500 at a crosshead speed of $0.5 \mathrm{~mm} / \mathrm{min}$ to obtain the extrusion of the post.

The punch was positioned to touch the post only, without stressing the surrounding dentinal walls. The load was applied on the apical surface of the slice in apical-coronal direction, with the purpose of preventing the conical shape of the canal from withstanding the dislodgement of the post.

Push-out strength data was in Newtons (N) which was converted to MegaPascals (MPa) by dividing the load by the bonded surface area.

In order to obtain the bonded surface area of each sample, we took pictures of the apical surface using

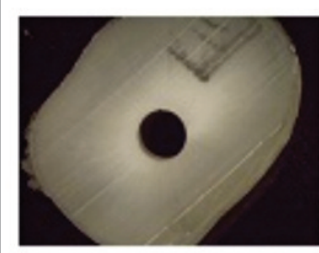

a) Group A

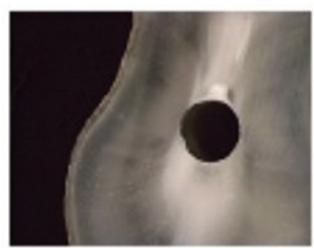

c) Group C

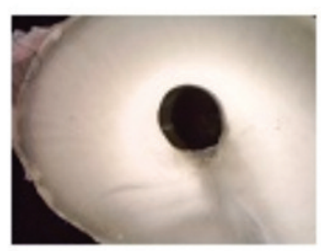

b) Group $B$

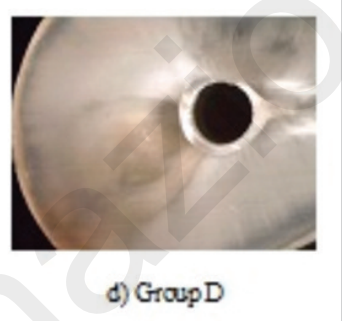

Figure 1. Slices of samples after the push-out test.

an optical microscope (Zeiss laser scan). We used for each picture the same angle of view and enlargement (50x) after the push-out test (Fig. 1).

Similarly, we took a picture of a marked size $(1 \mathrm{~mm})$. Image processing software provided with the optical microscope-Zeiss laser scan was used to analyze the pictures after calibrating the space using the marked size. The visible circumference size was found, following the line of the fracture.

Knowing the thickness of the sample $(1 \mathrm{~mm})$ and the taper of the apical surface of the post, we calculated the lateral surface area of a truncated cone which is the bonded surface area through the formula:

$S_{L}=\pi(R+r)\left[\left(h^{2}+(R-r)^{2}\right]^{0,5}\right.$, where $\mathrm{R}$ is the coronal post radius, $r$ the apical post radius, and $h$ the thickness of the slice.

Each section was submitted to the same procedure. Statistical analysis was performed using SPSS Inc, ver. 13.0, Chicago, IL, USA. Chi-squared test was used for statistical evaluation of proportions. In cases with more than 2 independent means we used the ANOVA test. A p-value of less than 0.05 was considered significant. A $95 \% \mathrm{Cl}$ was used in all analysis. In order to assure data reliability data were entered in two different personal computers by the two examiners, the two data files were compared in order to detect entry errors. The two files resulted identical.

\section{Results}

For each analyzed section we obtained the bond strength between the post and the dentin (MPa). Then, the average values, between the section of every single root, between the roots of the same group were calculated to follow up the variations of the bond strengths of the different groups. There are the results obtained in Table 1.

Results were analyzed using the ANOVA test. 
Table 1. Results of the bond strength between the post and the dentin.

\begin{tabular}{|c|c|c|c|c|c|}
\hline Group A & Samples & $\mathrm{MPa}$ & Group B & Samples & $\mathrm{MPa}$ \\
\hline$\overline{\mathrm{A} 1}$ & 3 & 9,24 & B1 & 4 & 18,73 \\
\hline $\mathrm{A} 2$ & 5 & 18,8 & B2 & 5 & 9,98 \\
\hline A3 & 5 & 6,854 & B3 & 5 & 15,01 \\
\hline A4 & 6 & 7,861 & B4 & 5 & 9,47 \\
\hline A5 & 6 & 6,08 & B5 & 5 & 6,25 \\
\hline A6 & 6 & 6,743 & $\mathrm{~B} 6$ & 5 & 10,14 \\
\hline A7 & 5 & 11,08 & B7 & 3 & 16,5 \\
\hline A8 & 5 & 7,8298 & B8 & 5 & 17,23 \\
\hline A9 & 4 & 8,52 & B9 & 3 & 11,33 \\
\hline \multirow[t]{2}{*}{ A10 } & 7 & 14,81 & B10 & 4 & 11,2 \\
\hline & & Average 7,026 & & & Average 12,584 \\
\hline Group C & Samples & $\mathrm{MPa}$ & Group D & Samples & $\mathrm{MPa}$ \\
\hline $\mathrm{C} 1$ & 5 & 5,01 & D1 & 5 & 5,54 \\
\hline $\mathrm{C} 2$ & 4 & 12,36 & D2 & 4 & 9,58 \\
\hline C3 & 4 & 13,87 & D3 & 4 & 5,55 \\
\hline C4 & 4 & 10,812 & D4 & 5 & 10,6 \\
\hline C5 & 5 & 6,05 & D5 & 4 & 11,07 \\
\hline $\mathrm{C} 6$ & 4 & 11,49 & $\mathrm{D} 6$ & 5 & 5,753 \\
\hline $\mathrm{C} 7$ & 4 & 11,85 & D7 & 4 & 4,43 \\
\hline C8 & 5 & 18,87 & D8 & 5 & 4,45 \\
\hline C9 & 4 & 14,78 & D9 & 5 & 4,41 \\
\hline $\mathrm{C} 10$ & 4 & 8,33 & D10 & 5 & 3,91 \\
\hline & & Average 11,34 & & & Average 6,52 \\
\hline
\end{tabular}

Table 2. Descriptives.

\begin{tabular}{|c|c|c|c|c|c|c|c|c|}
\hline \multicolumn{9}{|c|}{ Descriptives Mpa } \\
\hline & \multirow[t]{2}{*}{$\mathbf{N}$} & \multirow[t]{2}{*}{ Mean } & \multirow[t]{2}{*}{$\begin{array}{l}\text { Std. } \\
\text { Deviation }\end{array}$} & \multirow[t]{2}{*}{ Std. Error } & \multicolumn{2}{|c|}{$\begin{array}{l}95 \% \text { Confidence } \\
\text { Interval for Mean }\end{array}$} & \multirow[t]{2}{*}{ Minimum } & \multirow[t]{2}{*}{ Maximum } \\
\hline & & & & & Lower Bound & Upper Bound & & \\
\hline A & 10 & 9.7638 & 4.08128 & 1.29061 & 6.8442 & 12.6834 & 6.08 & 18.80 \\
\hline B & 10 & 12.5840 & 4.03647 & 1.27644 & 9.6965 & 15.4715 & 6.25 & 18.73 \\
\hline C & 10 & 11.3512 & 4.14027 & 1.30927 & 8.3894 & 14.3130 & 5.01 & 18.87 \\
\hline D & 10 & 6.4753 & 2.68710 & .84974 & 4.5531 & 8.3975 & 3.91 & 11.07 \\
\hline Total & 40 & 10.0436 & 4.31323 & .68198 & 8.6641 & 11.4230 & 3.91 & 18.87 \\
\hline
\end{tabular}

\section{Discussion and conclusions}

After the experimental study, the results (Tabs. 1, 2, Fig. 2) show that etching time is crucial in the cementation of the posts. The lowest bond strength values were found in Group D, where the etching step was not performed.

As far as the time of application of the orthophosphoric acid, comparing Groups A (15 seconds), B (30 seconds), and $\mathrm{C}$ (2 minutes), highest bond strength values obtained result in the group $\mathrm{B}$. Differences that are statistically significant occur between Group B and D and between $C$ and $D$, therefore etching for 15 s or eliminate the etching step with the acid ortophosphoric doesn't guarantee a satisfying bond strength. On the other hand etching for at least 30s guarantees a better bond strength, an over-etching doesn't improve or diminish bond strength. As a result, it would be interesting to analyze how the bond strength varies between $30 \mathrm{sec}$ onds and 2 minutes of application of the acid.
Yet, results cannot support the hypothesis of overetching time as an effective technique to improve the adhesion to the endodontic substrate or, at least, not considering the times of application of the acid for 2 minutes.

Literature is still very controversial about this issue because, even though acid etching allows to look for the collagen fibers which were destroyed during the endodontic treatment but which are necessary for the adhesion, over etching could be counter-productive and lead to losing the normal structure of the dentinal tubules (21-27).

Further studies are required to be carried out on this issue, taking into account the substrate, its characteristics to enable to provide for its deficiencies. By applying the proper operating procedures and valuing the state of the dental element, we should be able to choose the appropriate direct or indirect restoration, which could assure the most reliable guarantees of a long-term prognosis. 


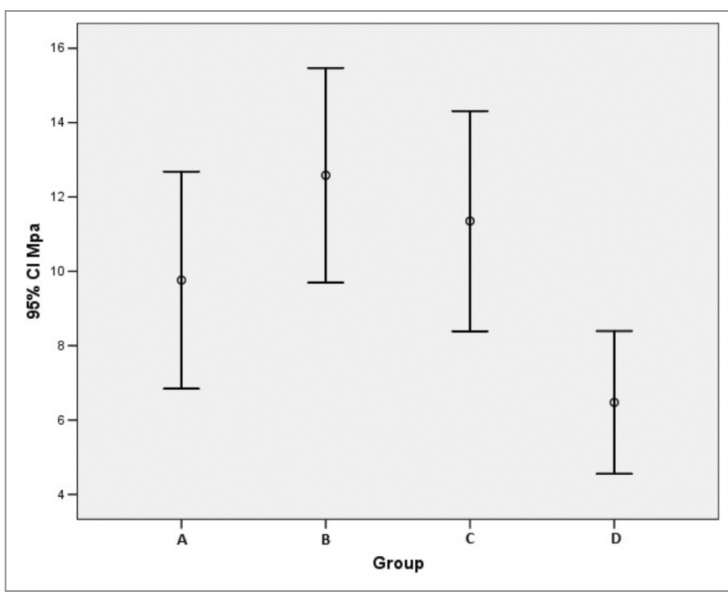

Figure 2. Range of value for every group.

\section{Manufacturer's details}

- Sweden \& Martina SPA, Via Veneto 10 - 35020 Due Carrare (PD) - Italy.

- OGNA Laboratori Farmaceutici, Via Figini, 41 Muggiò (MI) - Italy.

- DENTSPLY MAILLEFER, Chemin du Verger 3 1338 Ballaigues - Suisse.

- DMG Chemisch-Pharmazeutische Fabrik $\mathrm{GmbH}$, Elbgaustraße 248 - 22547 Hamburg - Germany.

- Remet s.a.s, Via Scarlatti $2-40033$ Casalecchio di Reno, Bologna - Italy.

- NORTON SAINT-GOBAIN, Worcester - 01606 Massachussetts - USA.

- Galdabini, Via Giovanni XXIII 183 - 21010 Cardano al Campo (VA) -Italy.

- Carl Zeiss Microlmaging GmbH, Standort Göttingen - Vertrieb - Germany.

\section{References}

1. Marshall GW Jr, Marshall SJ, Kinney JH, Balooch M. The dentin substrate: structure and properties related to bonding. J Dent. 1997;25(6): 441-58.

2. Perdigao J. Dentin bonding as a function of dentin structure. Dent Clin North Am. 2002;46(2):277-301.

3. Nakabayashi N, Kojima K, Masuhara E. The promotion of adhesion by the infiltration of monomers into tooth substrates. J Biomed Mater Res. 1982;16(3):265-73.

4. Brännström M, Noredenvall KJ. The effect of acid etching on enamel, dentin, and the inner surface of the resin restoration: a scanning electron microscopic investigation. J Dent Res. 1977 Aug;56(8):917-23.

5. Ferrari M, Mannocci F, Vichi A, Cagidiaco MC, Mjör IA. Bonding to root canal: structural characteristics of the substrate. Am J Dent. 2000 Oct;13(5):255-60.

6. Lopes GC, Cardoso Pde C, Vieira LC, Baratieri LN. Microtensile bond strength to root canal vs pulp chamber dentin: effect of bonding strategies. J Adhes Dent. 2004 Summer; 6(2):129-33.

7. Tjan $\mathrm{AH}, \mathrm{Nemetz} \mathrm{H}$. Effect of eugenol-containing endodontic sealer on retention of prefabricated posts luted with adhesive composite resin cement. Quint Int. 1992;23(12):839-44.
8. Windley W 3rd, Ritter A, Trope M. The effect of short-term calcium hydroxide treatment on dentin bond strengths to composite resin. Dent Traumatol. 2003 Apr;19(2):79-84.

9. Perdigão J, Gomes G, Augusto V. The effect of dowel space on the bond strengths of fiber posts. J Prosthodont. 2007 MayJun;16(3):154-64

10. Morris MD, Lee KW, Agee KA, Bouillaguet S, Pashley DH. Effects of sodium hypochlorite and RC-Prep on bond strenghts of resin cement to endodontic surfaces. J Endod. 2001;27(12):753-7.

11. Hayashi M, Takahashi $Y$, Hirai M, Iwami $Y$, Imazato S, Ebisu $\mathrm{S}$. Effect of endodontic irrigation on bonding of resin cement to radicular dentin. Eur J Oral Sci. 2005 Feb;113(1):70-6.

12. Wattanawongpitak N, Nakajima M, Ikeda M, Foxton RM, Tagami J. Microtensile bond strength of etch-and-rinse and self-etching adhesives to intrapulpal dentin after endodontic irrigation and setting of root canal sealer. J Adhes Dent. 2009 Feb;11(1):57-64.

13. Dietschi D, Duc O, Krejci I, Sadan A. Biomechanical considerations for the restoration of endodontically treated teeth: a systematic review of the literature - Part 1. Composition and micro- and macrostructure alterations. Quintessence Int. 2007 Oct;38(9):733-43.

14. Serafino C, Gallina G, Cumbo E, Ferrari M. Surface debris of canal walls after post space preparation in endodontically treated teeth: a scanning electron microscopic study. Oral Surg Oral Med Oral Pathol Oral Radiol Endod. 2004 Mar;97(3):381-7.

15. Soares PV, Santos-Filho PC, Martins LR, Soares CJ. Influence of restorative technique on the biomechanical behavior of endodontically treated maxillary premolars. Part I: fracture resistance and fracture mode. J Prosthet Dent. 2008 Jan;99(1):30-7.

16. Musikant BL, Deutsch AS. Post design and his impact on the root and crown. Compend Contin Educ Dent. 2006 Feb;27(2):130-133.

17. Ferrari M, Cagidiaco MC, Goracci C, Vichi A, Mason PN Radovic I, Tay F. Long-term retrospective study of the clinical performance of fiber post. Am J Dent. 2007;20(5):28791.

18. Salameh Z, Sorrentino R, Ounsi HF, Goracci C, Tashkandi E, Tay FR, Ferrari M. Effect of different all-ceramic crown system on fracture resistance and failure pattern of endodontically treated maxillary premolars restored with and without glass fiber posts. J Endod. 2007;33(7): 848-51.

19. Bouillaguet S, Troesch S, Wataha JC, Krejci I, Meyer JM, Pashley DH. Microtensile bond strenght between adhesive cements and root canal dentin. Dent Mater. 2003;19 (3):199-205.

20. Tay FR, Loushine RJ, Lambrechts P, Weller RN, Pashley $\mathrm{DH}$. Geometric factors affecting dentin bonding in root canals: a theoretical modeling approach. J Endod. 2005 Aug;31(8):584-9.

21. Pioch $\mathrm{T}$, Stotz $\mathrm{S}$, Buff E, Duschner H, Staehle HJ. Influence of different etching times on hybrid layer formation and tensile bond strength. Am J Dent. 1998 Oct;11(5):202-6.

22. Hashimoto M, Ohno H, Endo K, Kaga M, Sano H, Oguch $H$. The effect of hybrid layer thickness on bond strength: demineralized dentin zone of the hybrid layer. Dent Mater. 2000 Nov;16(6):406-11.

23. Hashimoto M, Ohno H, Kaga M, Sano H, Tay FR, Oguch $H$, Araki $Y$, Kubota M.Over-etching effects on micro-tensile bond strength and failure patterns for two dentin bonding systems. J Dent. 2002 Feb-Mar;30(2-3):99-105.

24. Lopes GC, Vieira LC, Monteiro S Jr, Caldeira de Andrada MA, Baratieri CM. Dentin bonding: effect of degree of mineralization and acid etching time. Oper Dent. 2003 JulAug;28(4):429-39. 
25. Abu-Hanna A, Gordan VV, Mjor I. The effect of variation in etching times on dentin bonding. Gen Dent. 2004 JanFeb;52(1):28-33.

26. Ahid F, Andrade MF, Campos EA, Luscino F, Vaz LG. Influence of different dentin etching times and concentrations and air-abrasion technique on dentin microtensile bond strength. Am J Dent. 2004 Dec;17(6):447-50.

27. Brajdić D, Krznarić OM, Azinović Z, Macan D, Baranović M. Influence of different etching times on dentin surface morphology. Coll Antropol. 2008 Sep;32(3):893-900. 